\title{
ADOLF LOOS E A NÃO ORNAMENTAÇÃO
}

Dayane Tieme Carrenho', Gabriel Pimenta', Jaqueline Naomi Haga', Lucas Blaia', Mayara Motta', Rogério Gabriel', Korina Costa².

${ }^{1}$ Discente do curso de Arquitetura e Urbanismo da Universidade do Oeste Paulista - UNOESTE. ${ }^{2}$ Docente do Curso de A Arquitetura e Urbanismo da Universidade do Oeste Paulista - UNOESTE

\section{RESUMO}

Arquiteto e teórico, Adolf Loos foi um grande pensador no final do século XIX ao início do século $X X$, um dos criadores do modernismo. Na época, foi um dos pioneiros a romper com o historicismo, idealizando o abandono do ornamento e projetos mais limpos e racionais. Por meio de suas obras, deu início a novas características arquitetônicas, como o pé direito de diferentes alturas, o Raumplan, e seus inovadores terraço, presentes em grande parte de seus projetos. Nesse artigo, iremos analisar suas características e obras, ampliando o conhecimento na arquitetura pré-modernista e compreendendo as teorias de Adolf Loos, ao projetar uma arquitetura simples e nula de decorações.

Palavras-chave: Adolf Loos, arquitetura, pré-modernismo, ornamento, funcionalismo

\section{INTRODUÇÃO}

A história da arquitetura é composta por nomes que a revolucionaram. Adolf Loos foi um desses personagens. Sua contribuição a ela refletiu para uma nova visão, abrindo novos caminhos na arquitetura, revolucionando seu tempo e influenciando as gerações futuras.

De todos os seus feitos, sua maior contribuição foram seus escritos destacando-se o ensaio "Ornamento e Delito", provocando repercussão internacional.

Sua teoria ainda é muito aplicada atualmente, pois ele observava o passado, criticava o presente e pensava no futuro.

\section{TEORIA E PENSAMENTO DE ADOLF LOOS}

Enquanto o movimento Art-Nouveau, este ligado a um estilo estético voltado para o design e arquitetura e acoplado ao arts $\&$ crafts que teve seu destaque na Belle époque, encontrava-se em seu auge entre o final do século XIX e inicio do século $X X$, surgiu o protorracionalismo que pode ser considerado o oposto da Art-Nouveau, este confrontava o estilo da arte com ornamentação exuberante. O protorracionalismo, propôs o emprego de novas técnicas, das formas mais simples, onde trazia economia e eliminava o supérfluo e o desperdício, apresentando assim uma arquitetura mais racional, que refletia no momento social e econômico da época. 
E é nesse momento de ruptura que Loos se enquadra como personagem de suma importância tornando-se um exímio crítico da arquitetura na época, adotando o pensamento que a função tinha que seguir as necessidades do homem, ele era adepto as formas simples e puras.

Pode -se destacar dois fatores do seu modo de pensar: desvinculação da arquitetura com a arte, na qual a arte não é associada a utilidade, por isso não pode ser considerada arquitetura, e o abandono do ornamentos, se opondo ao desperdício, como uma forma correta e moral na utilização dos materiais empregados.

Para Adolf Loos, a arquitetura não é arte, porque a arquitetura precisa agradar a todos e a arte não precisa agradar a ninguém. Ele fundamenta-se no principio de que ela (arquitetura) deve ser útil e baseada, em sua essência, na racionalidade como cita:

A casa tem de ser amada por todos. Ao invés da obra de arte que não tem de ser amada por ninguém. A obra de arte é um assunto privado do artista. A casa não o é. A obra de arte introduz-se no mundo sem que exista necessidade dela. A casa cumpre sempre uma necessidade. (...) A obra de arte quer arrancar as pessoas da sua comodidade. A casa tem de servir a comodidade. A obra de arte é revolucionária, a casa é conservadora. A obra de arte ensina novos caminhos à humanidade e pensa no futuro. A casa pensa no presente. (Loos).

Para Loos, a arte em seu principio busca o prazer, já a arquitetura se coloca à funcionalidade. Para ele não há lugar para irracionalidade na arquitetura, já que a mesma é uma resposta as necessidades, tornando-a um resultado de atitude lógica.

Assim a arquitetura é composta pela utilidade e necessidade, qualquer objeto ( de um utensílio à um edifício) devem responder a um principio de função. Ele só considerava a “arquitetura da memória" pertencente a arte composta por monumentos e sepulcros, já que significam um habitar poético. Adolf Loos acreditava que não se pode projetar em arquitetura com o intuito de fazer da beleza um fim a ser atingido em si mesma, mas com a finalidade de alcançar sua perfeita utilidade." O espirito moderno exige, antes de tudo, que o objeto de uso seja prático. Para ele, a beleza significa máxima perfeição. E, dado que, o que não é prático nunca é perfeito, tão pouco pode ser belo". (Loos).

Desse modo a arte não deve interferir na produção dos objetos, no qual devem ser produzidos industrialmente porque são mais práticos e, consequentemente, os tornam mais eficazes para o uso da sociedade, pois quando o artista interfere na produção dos objetos, estes se tornam mais caros e inacessíveis. 
Loos não admite a presença do ornamento tanto na arquitetura quanto nos objetos por vários motivos. Um deles é de que ornamento não pode aumentar a alegria de viver de um homem culto. Ele só o aceita quando este define o ornamentista, quando o seu emprego torna a vida deste individuo mais feliz, sendo ele (ornamento) tudo que a pessoa sabe e conhece. Este não é o caso de um modernista, que possui cultura e intelecto suficiente para ser conhecedor de outras artes, como Bethoven e Tristão. “...Nós temos a arte que substitui o ornamento...". (Loos, 1908).

Suas ideias não foram bem aceitas, pois grande parte da população ainda não vivia "em seu tempo", mas com ideias e crenças do passado ainda ligadas à tradições. Estas pessoas ainda apegadas ao ornamento, seja ele decorativo ou ate mesmo na elaboração de seu prato de comida, acabavam por ter uma vida mais cara e lenta, ficando atrasadas em relação ao homem moderno.

Um objeto ornamentado, ainda que seja durável, ficará ultrapassado pois o ornamento é uma tendência mutável baseada no gosto das pessoas, fazendo com que elas substituam esses objetos assim que surgirem outras novas tendências.

Loos escreve que, o que caracterizava e representava o tempo em que viviam, é justamente a falta do ornamento, considerando este fato uma vitória sobre os séculos passado que não foram capazes de se desprender dele. Isto marca o inicio de uma nova civilização onde a presença da figura lisa da parede é algo tão normal quanto a presença do ornamento nos séculos passados.

Suas idéias foram concretizadas em seus projetos, como podemos observar em alguns deles, tais como a Looshaus e a Casa Steiner, onde era empregada a limpeza visual e que tinham como principal objetivo a funcionalidade, fato que impressionou até mesmo os contemporâneos da época.

Procurava empregar soluções e métodos de construções mais simples, considerando a ornamentação um crime à economia, pois se tal não atende as necessidades práticas, é simplesmente imoral. Essa busca pelo purismo arquitetônico reflete sua personalidade e também o conceito evolutivo da arquitetura moderna que dava espaço ao progresso, a expressão da modernidade.

Ao longo de sua vida agregou diversos ofícios (inclusive como pedreiro), que acabaram por influenciar sua opinião de que o arquiteto deve aprender na prática a técnica.

Suas obras são simples e racionais. Realizava vários estudos de plantas e cortes para aplicar da melhor maneira sua teoria de Raumplam, que é a altimetria dos espaços independentes na distribuição da edificação conforme suas funções, poupando assim espaço e dinheiro, tornando o 
projeto mais racional e funcional. Com a ausência do ornamento em suas fachadas, Loos investia no interior usando materiais nobres, como o mármore e madeira.

Loos não chegava a condenar o ornamento em si e sim sua relação que era desligada da realidade funcional e construtiva de suas obras. Ele não só se destacava pelas suas obras mas, principalmente, pelas suas teorias sobre a arquitetura moderna, que acabaram por influenciar grandes nomes da arquitetura moderna como Walter Gropius e Le Courbusier.

Em seus edifícios, Adolf Loos normalmente começa com um volume principal em que o espaço, configuração e elementos seguem as regras e composição da arquitetura clássica. Ele organiza o interior desse volume com cubos menores, caixas de retângulos e cilindros dispostos em um quebra-cabeça volumétrico. Determina a organização interna dos seus edifícios e utiliza regularmente saliências do bloco principal para criar outras áreas do edifício, tais como terraços, destacando maior preocupação pelo elemento da estrutura do que com a adoção de elementos decorativos. Como uma de suas principais obras destacam-se a Villa Müller e a Casa Steiner.

\subsection{RESIDÊNCIA STEINER}

$\mathrm{O}$ arquiteto ainda estava no começo de sua carreira, quando construiu e projetou a Casa Steiner localizada em Viena, na Áustria em 1910. Houve uma grande aceitação da mesma, comparando-se com outras obras antigas, e rapidamente tornando-se um exemplo de arquitetura racionalista da época.

A modernidade da Steiner House não é tanto o resultado de um processo de abstração, mas sim técnica de construção, testados por uma longa tradição. Os exemplos são a ausência absoluta de decoração nas paredes exteriores (rebocadas em argamassa comum e cal), como as antigas casas de Viena, e também a adoção do telhado de zinco curvado (inserida a partir da cultura histórica da construção local).

Nos diferentes pisos do imóvel, os quartos são seguidos com continuidade, juntamente com grandes corredores. O porão abriga a garagem (acessível a partir da rua através de uma rampa), e a sala da caldeira (que abriga a casa com entrada separada). No piso térreo há uma sala que contem uma sala de jantar, quarto e sala de música dividida por um sistema de cortina. 0 plano é acessível a partir do jardim através de um sistema de escadas encostadas nas laterais do prospecto e na estrada com uma escada central. No primeiro andar ficam os quartos, dois banheiros, o estúdio de pintura de Lilly Steiner, uma sala para as crianças e no segundo andar estão dispostos vários ambientes de serviço. Os quartos foram caracterizados por camas em latão, estofados florais qualificados, móveis estofados em madeira pintada em branco. A sala de pintura 
Lilly Steiner é separada da área de dormir e iluminado por uma grande janela que perfura a curva do teto com revestimento em metal. Os vários andares são ligados por uma escada em espiral e servidos por uma escada de dois lances ligando o térreo ao primeiro andar.

Por seu princípio intimista, na casa Steiner não existe correspondência da relação entre o interior e o exterior, com exceção da fachada do jardim. A fachada principal do mesmo tem uma composição marcadamente clássica, com uma distribuição simétrica das aberturas, uma perfeita equivalência de sólidos e vazios, incluindo a estrutura lateral e um terraço que é acessado a partir das laterais.

A residência apresenta uma composição simétrica no que diz respeito à distribuição das aberturas, mais uma diversidade na sua concepção. Já na fachada principal a janela do lado direito é menor do que a da esquerda, e as laterais não seguem uma simetria.

Na Casa Steiner, Loos só conseguiu construir um andar acima do nível da rua. Isso o levou a criar um teto redondo que está virado para a mesma. Esta cobertura achata o ápice e faz com que os dois andares adicionais, que estão de frente para o jardim, não tenham vista para a rua.

O teto curvo foi uma escolha interessante, pois não só foi uma ruptura em linha reta a partir de telhado de duas águas como também uma inovação. Foi feito para demonstrar a certeza da forma e da economia de espaço, provando que as tradições podem ser manipuladas e libertas completamente, por um propósito funcional e não estética.

O telhado curvo foi substituído cerca de vinte anos após a sua construção por um telhado inclinado em um ângulo considerável, seguindo a tipologia do edifícios da área, destruindo a unidade do projeto de Loos, que mais tarde foi restaurado e voltou a sua forma original.

\subsection{VILLA MÜLLER}

Construída, a noroeste do centro de Praga, entre os anos 1928 à1930, para um casal de proprietários de uma empresa de construção pioneira no uso de concreto armado, o senhor Frantsek Müller e sua esposa Milada.

Para Loos, essa obra é a definição de um projeto residencial moderno, onde há o rompimento da clássica ordem de verticalização dos pisos e passa-se a criar habitações com várias alturas e espaços únicos unidos por escadas, o Raunplam.

Houve grande colaboração entre o cliente (Senhor Müller) e Adolf Loos o que resultou numa construção diferenciada e sofisticada. A residência possui três de suas fachadas voltadas para áreas publicas e uma para terrenos privados. 
Sendo o terreno de implantação inclinado, este teve uma influencia crucial na estratégia da obra, onde ele mais pode expressar suas ideias.

Devido ao fato de seus espaços não serem compreendidos, a casa Muller não foi qualificada como moderna.

Além do casal, viviam na residência algumas pessoas do serviço doméstico, onde Loos separou a área reservada da família da de serviço, assim como procurou separar também o espaço público externo dos espaços privados internos, realizando ambientes para pessoas específicas com suas necessidades individuais.

A prioridade da casa era ser construída para quem a habitava, e não para quem a via de fora. A circulação no interior da residência se dá a fim de evitar o centro de forma que as pessoas entrem por um lado e saiam por outro.

Exteriormente, caracteriza-se pela forma cubica com varanda e telhado plano, fachada branca e sem adorno algum, com irregularidades nas janelas dos quartos que são bem perceptíveis quando avistadas pelo lado externo.

O muro que cerca a residência é de tijolo maciço coberto com barras de metal, já a decoração do jardim foi um trabalhado realizado por um grupo de paisagistas alemães juntamente com Adolf Loos, sendo estes Camilo Schneider, Karl Hermann Matern Furste.

Interiormente Loos foi mais inovador, onde cada espaço requeria uma altura diferente de modo que as subidas e descidas sejam ao mesmo tempo funcionais. Os volumes onde os espaços são mais amplos têm pé direito maior.

A mobília da Villa possui uma mistura eclética de estilos. A peça central da sala é uma mesa redonda com capacidade para até 18 pessoas e é fabricado em mogno e granito com uma perna octogonal.

No projeto foram utilizados acabamento em mármore, pedras, madeira e seda. No salão principal foi utilizado mármore verde para cobrir as paredes e colunas de madeira de mogno na sala de jantar, azulejos na biblioteca e madeira de limão no gabinete.

$\mathrm{Na}$ entrada os azulejos são escuros, as paredes pintadas em brancos com painéis de madeira clara e o teto na cor azul profundo. A casa possui cerca de 600 metros quadrados.

\section{CONCLUSÃO}

Ainda hoje, os fundamentos de Loos provocam críticas e contraposições, pois ele afirma que a arquitetura é um despertar de sentimentos do homem, sendo assim ela não seria considerada como arte?! 
Encontro de Ensino, Pesquisa e Extensão, Presidente Prudente, 21 a 24 de outubro, 2013

Adolf Loos, abriu um novo horizonte para a história da arquitetura, no qual suas obras influenciaram arquitetos como Walter Gropius e Le Corbusier.

A questão do desperdício tornou-se um ato que transcende as barreiras da arquitetura envolvendo questões éticas, morais e sociais durante as construções dos edifícios. Ele trouxe abordagens que são atemporais, olhando para o futuro, tornando-se um dos mais importantes personagens do primeiro modernismo.

\section{REFEÊNCIAS}

Glynn, Symon. Michaelerplatz 3 ("Looshaus") Vienna. Disponível em: <http://www.galinsky.com>. Acesso em: 01 mar. 2013.

Fracalossi, Igor. "Notas sobre o ornamento (Parte 2)". Disponível em: <http://www.archdaily.com.br/21587>. Acessado em: 02 Jun. 2013.

<http://www.greatbuildings.com/architects/Adolf_Loos> Acessado em: 02 jun. 2013.

<http://www.vitruvio.ch/arc/masters/loos.php>. Acessado em: 30 mai. 2013.

<http://www.mullerovavila.cz/?q=english>. Acessado em: 01 jun. 2013.

Bosel, Richard; Vitale, Zanchettin. Adolf Loos. Architettura. Utilità e decoro. Desenvolido pela GNAM Galleria Nazionale d'Arte Moderna. Disponível em:

<http://www.archimagazine.com/aloos.htm>. Acessado em: 01 jun. 2013.

Besser, Joern, Liebscher Stephan. Adolf Loos The Life - The Theories - Analysis of the Villa Mueller. Disponível em: <http://www.desyndicate.de/inhalt/downloads/Adolf_Loos-The_Life-

The_Theories-Villa_Mueller.pdf>. Acessado em: 02 jun. 2013.

O Espírito Moderno \# 1. Disponível em: <http://had2.files.wordpress.com/2010/04/adolfloos.pdf>. Acessado em: 02 jun. 2013.

Adolf Loos. Disponível em: <http://www.eesc.usp.br/babel/loos_biografia.htm>. Acessado em: 28 mai. 2013.

Biografia: Adolf Loos. Disponível em: <http://www.arctecart.com.br/2011/07/arquitetos-adolfloos-biografia.html>. Acessado em: 29 mai. 2013.

<www.greatbuildings.com>. Acessado em: 02 jun. 2013.

Benevolo, Leonardo. História da arquitetura moderna. São Paulo: Perspectiva, 1976. 